\title{
УСТОЙЧИВОЕ РАЗВИТИЕ МИРОВОЙ ЭКОНОМИКИ В УСЛОВИЯХ ПАНДЕМИИ
}

\author{
(c) 2021 Иванова Дарья Геннадьевна \\ кандидат экономических наук, доцент кафедры «Мировой экономики» \\ Ростовский государственный экономический университет, Россия, Ростов-на-Дону \\ E-mail: ivanova753@yandex.ru
}

Статья посвящена исследованию проблем устойчивого развития мировой экономики в период пандемии COVID-19. Рассмотрены зеленые технологии как инструмент повышения устойчивого развития. Особое внимание уделено стратегии низкоуглеродного климатически устойчивого развития, а также другим национальным стратегиям в данной области.

Ключевые слова: устойчивое развитие, пандемия, зеленая экономика, международное сотрудничество, национальные стратегии.

В условиях пандемии проблема обеспечения устойчивого развития мировой экономики представляется особенно актуальной.

Пандемия COVID-19 продемонстрировала, что все предыдущие достижения по сокращению бедности, голода, обеспечению здравоохранения и повышению благосостояния могут быть обращены вспять, если только мировое сообщество не предпримет таких же решительных действий по реализации целей устойчивого развития (далее - ЦУР), какие сейчас принимаются для противодействия распространению коронавирусной инфекции. Канадский Международный институт устойчивого развития (IISD) отмечает, что беспрецедентные глобальные потрясения усугубили последствия неравенства, поскольку бедные страны испытывают сравнительно более серьезные последствия [1]. Даже в развивающихся странах обычные работники, составляющие основу сектора услуг, оказались более уязвимыми перед коронавирусной инфекцией и менее готовыми выдержать финансовые последствия пандемии.

Вместе с тем, пандемия COVID-19 создала и немало косвенных препятствий на пути к устойчивому развитию. Например, в периоды кризиса как никогда возрастает потребность в качественных и своевременных данных, необходимых для принятия решений. Однако сегодня наблюдаются серьезные трудности в процессе сбора и обработки экономической и финансовой статистики, в том числе, касающейся «Преобразование нашего мира: Повестка дня в области устойчивого развития на период до 2030 года» [2] (далее - Повестка-2030) и оценки прогресса в достижении ЦУР. Заметный косвенный эф- фект заключается и в том, что распространение инфекции и необходимость борьбы с ней в значительной степени отвлекают организационные ресурсы правительств и препятствуют координации действий в рамках Повестки-2030.

Следует отметить, что одним из инструментов достижения целей устойчивого развития является внедрение зеленой экономики по всему миру. Эффективная зеленая экономика способствует скорейшему достижению целей устойчивого развития не только в экономике, но и в сфере экологии. Приоритетными направлениями зеленой экономики на сегодняшний день являются водное и лесное хозяйства, сельское хозяйство, рыболовство, энергетика, транспорт, промышленность, туризм, строительство, модернизация системы отходов. Именно эти направления загрязняют окружающую среду в большей степени, однако при зеленой экономике они раскрывают огромный потенциал для реализации модели зеленого роста. Поэтому именно реализация зеленой экономики является одним из действенных механизмов повышения устойчивого развития в период пандемии. Стратегия зеленого роста направлена на снижение экологической нагрузки, которая, в первую очередь, обусловлена масштабами хозяйственной деятельности. К отрицательным проявлениям хозяйственной деятельности относится повышение количества отходов и вредных выбросов. Под отходами понимают строительный мусор, автомобили, которые не пригодны для езды, бытовая техника и иные схожие товары, а также отходы биомассы. И все же, самое негативное влияние на окружающую среду оказывает промышленное производство. Энергетика, об- 
рабатывающая и добывающая промышленность несут в себе самые опасные последствия для экологии, так как больше четверти всех опасных выбросов исходит из сектора промышленности. Постоянный рост промышленного производства ежегодно увеличивает нагрузку на окружающую среду, что неуклонно ведет к обострению экологических проблем, а, следовательно, и замедляет процесс достижения устойчивого развития.

Благодаря зеленым технологиям повышается возможность реализации инновационного развития в странах, повышения эффективности производства, развития технологий в энергетике, сельском хозяйстве и иных важных сферах. Для эффективного внедрения экологических технологий необходима адекватная политика государства, которая должна опираться на возможность самостоятельных разработок инноваций, участии в международном обмене информацией и технологиями.

При проведении данной политики государство должно принимать во внимание необходимость технологического развития как на макроуровне, так и на микроуровне, а также должно быть четкое понимание последствий внедрения данных технологий.

На сегодняшний день почти все страны в той или иной мере используют зеленые технологии. Они присутствуют даже в секторе информационных технологий, например, экологически ориентированные информационные технологии, которые подразумевают высокий уровень инновационной активности, новое технологическое оборудование, при использовании которого рационально задействованы ресурсы. Однако основным направлением зеленой экономики все же остается сектор энергетики. Огромное внимание уделяется поиску более чистых и возобновляемых источников энергии.

Важнейшую роль в повышении устойчивости играет международное сотрудничество, особенно в период пандемии. Оно ориентировано на широкий круг задач, но главные из них касаются экологии. В виду этого основными направлениями сотрудничества являются обмен знаниями и технологиями в области достижения устойчивого развития, решение вопросов координации научно-исследовательской деятельности по всему миру, взаимодействие стран по реализации стратегии зеленого роста, поддержка внедрения зеленых технологий в различных странах.

Также необходимым механизмом для повы- шения устойчивого развития является совместная стратегия низкоуглеродного климатически устойчивого развития. Мир сталкивается с изменением климата, что негативно отражается во всех сферах жизнедеятельности, поэтому совместными усилиями необходимо как можно скорее обеспечивать меры по борьбе с изменением климата. Многие государства берут на себя обязательства по снижению и ограничению вредных выбросов в атмосферу. Так, в развитых странах приняты долгосрочные программы по снижению количества вредных выбросов вплоть до 80\% на период до 2050 года.

Россия присоединилась к Парижскому климатическому соглашению ООН в 2019 г. и взяла на себя обязательства по предотвращению роста глобальной температуры на 1,5-2о C, а также значительному сокращению выбросов парниковых газов (ПГ) к середине XXI в. На 2030 г. установлена национальная цель - сократить выбросы ПГ до 70\% относительно уровня 1990 г. Разрабатываемая Минэкономразвития России Стратегия социально-экономического развития с низким уровнем выбросов ПГ до 2050 г. предусматривает ряд сценариев, связанных с осуществлением мер климатической политики, включая низкоуглеродное развитие энергетики, промышленности, транспорта и других отраслей [3].

Однако успешное достижение данной программы требует внешних условий для ее реализации, таких как низкоуглеродное развитие развивающихся стран, таких как Индия и Китай. В Китае и Индии, в свою очередь, показатели объемов выбросов только растут, а весь мировой объем выбросов на 80\% обусловлен этими двумя странами. К сожалению, они не выработали политику по снижению вредных выбросов, так как, например, у Индии приоритетным направлением является искоренение нищеты, поэтому переход к зеленым технологиям для Индии пока не возможен. Снижение вредных выбросов у таких стран как Мексика, Корея, Индонезия напрямую зависит от внешней помощи, а у ОАЭ, Саудовской Аравии, Катара и Кувейта есть опасения, что переход на низкоуглеродное развитие послужит снижением спроса на нефть. Остальные страны, в том числе, и островные оказывают совершенно незначительное влияние на мировые выбросы, поэтому эти довольно уязвимы к изменению климата и выступают за немедленное и остронеобходимое снижение выбросов парниковых газов в атмосферу. 
Правительства многих стран уже внедряют и разрабатывают политику по предотвращению изменения климата, сокращению выбросов вредных веществ в атмосферу, а также политику по эффективному и устойчивому социальноэкономическому развитию. Стратегии по снижению выбросов не только способствуют решению экологических проблем, но и социальных и даже экономических, которые также требует усиленных мер для достижения устойчивого развития.

Финансовое содействие международному развитию в области изменения климата является важнейшим аспектом в области устойчивого развития на сегодняшний день. Под этим содействием подразумевается предоставление дополнительных финансовых ресурсов, а не замещение одного вида помощи другим. Ежегодно объемы финансирования в развивающиеся страны увеличиваются, а инструменты достижения устойчивого развития становятся все более инновационными и действенными. Одним из инструментов финансовой помощи являются инвестиционные фонды, которые используются для проверки степени трансформационных изменений в направлении низкоуглеродного и климатически устойчивого развития путем финансирования развивающихся стран множественными банками. Так, Стратегический климатический фонд обеспечивает финансирование целевых программ, целью которых является обеспечение новых секторальных подходов к устойчивому развитию, а Фонд чистых технологий предоставляет финансирование для применения низкоуглеродных технологий, которые используются для сокращения объема парниковых газов в атмосферу. Такие фонды носят характер временных механизмов обеспечения финансовой базы для достижения устойчивого развития. Существуют также и национальные финансовые фонды, которые управляют денежными потоками в конкретной стране. Благодаря таким фондам государства могут аккумулировать все средства из различных источников, которые будут направлена на климатические, социальные или экономические проекты по повышению устойчивого развития.

Разработка национальных стратегий устойчивого развития в каждой стране значительно отличается, так как для результативности процесса необходимо учитывать особенности каждой страны, уделять внимание различным составляющим устойчивого разви- тия. Так, например, в Японии основным направлением является защита окружающей среды, а в Киргизии - обеспечение экономического роста и борьба с нищетой и бедностью. Также стратегии в разных странах отличаются способами координации политики по устойчивому развитию, частотой изменения направлений стратегии, мониторингом успехов по проделанной работе. Важнейшими целями в области устойчивого развития для США являются поддержание благоприятной окружающей среды, экономическое процветание, справедливые и равные условия для населения страны в возможностях социального, экономического и экологического характера, а также справедливая система управления.

Стратегия, которую реализует Европейский союз, является примером для многих стран, так как она охватывает все сферы устойчивого развития, имеет все необходимые целевые показатели, комплекс мер по мониторингу достижений в области устойчивого развития. Основными аспектами данной стратегии является решение проблем изменения климата, эффективного использования природных ресурсов, поддержания здоровья населения, обеспечение экологически чистым транспортом и использования чистой энергетики. Осуществляется регулярный мониторинг достижений в области устойчивого развития, что позволяет провести анализ успехов и проблем. Особое внимание в данной стратегии уделяется повышению качества образования, научным исследованиям в широком спектре областей, финансовым механизмам. Для мониторинга результативности каждые два года формируются доклады о достижении устойчивого развития и выносятся на обсуждение в Европейский союз.

Существующая система многостороннего регулирования свидетельствует о том, что проблемы, связанные с разработкой мер по взаимодействию стран и реализации программ устойчивого развития возможно решить достаточно эффективно на региональном уровне. Из этого следует, что важным механизмом повышения устойчивого развития является региональное сотрудничество. Во многих региональных соглашениях прописаны ожидаемые результаты сотрудничества, в частности:

- снижение вредных выбросов в атмосферу, что приведет к улучшению состояния здоровья населения и в результате снизит количество заболеваний, связанных с загрязнением окружаю- 
щей среды;

- рост производительности, снижение издержек и сокращение ущерба окружающей среде;

- эффективное сотрудничества в области охраны природы;

- сокращение числа заболеваний, связанных с плохим качеством питьевой воды и отсутствием санитарии;

- снижение объемов использования сырья за счет более эффективного его потребления;

- информирование населения по вопросам охраны окружающей среды, воспитания ответственного отношения к природным ресурсам.

Для того, чтобы сформировать область приоритетных направлений для успешного движения общества, требуется разработать экспертные предложения от гражданского общества. Все большую популярность приобретают институты устойчивого развития, которые способствуют совместным действиям экспертов и гражданского общества по реализации поставленных задач в данной области. Успешное функционирование институтов устойчивого развития имеет большое значение для всего мирового сообщества, оно предполагает осуществление совместных действий, принятие правил поведения и активное участие населения планеты в области достижения устойчивого развития.

Таким образом, успешное функционирование институтов устойчивого развития, правительств, международных объединений и даже отдельных лиц предполагает успешное достижение устойчивого развития как на национальном, так и на международном уровнях, что является особенно актуальным в условиях пандемии.

\section{Библиографический список}

1. Достижение ЦУР в условиях пандемии COVID-19: роль государств и высших органов аудита. Дайджест Департамента международного и регионального сотрудничества URL: https://ach.gov.ru/upload/pdf/Covid-19SDG.PDF (дата обращения 26.06.2021)

2. Официальный сайт Организации объединённых наций URL: https://unctad.org/system/files/officialdocument/ares70d1_ru.pdf (дата обращения 25.06.2021)

3. Официальный сайт Правительства Российской Федерации URL: https://www.economy.gov.ru/material/file/ba bacbb75d32d90e28d3298582d13a75/proekt_strategii.pdf (дата обращения 26.06.2021) 